OPEN ACCESS

Edited by:

Mauricio Antonio Retamal, Universidad del Desarrollo, Chile

Reviewed by:

Fabrice Cognasse

Scientific Affairs, the

Rhone-Alpes-Auvergne Regional Branch of the French National Blood

System, France

Mikko Juhani Nikinmaa,

University of Turku, Finland

*Correspondence:

Lars Kaestne

lars_kaestner@me.com

${ }^{\dagger}$ These authors have contributed equally to this work

Specialty section:

This article was submitted to Membrane Physiology and Membrane

Biophysics,

a section of the journal

Frontiers in Physiology

Received: 21 June 2017

Accepted: 23 August 2017

Published: 06 September 2017

Citation:

Hertz L, Huisjes R, Llaudet-Planas E,

Petkova-Kirova P, Makhro A,

Danielczok JG, Egee S, del Mar

Mañú-Pereira $M$, van Wijk $R$, Vives

Corrons J-L, Bogdanova A and

Kaestner L (2017) Is Increased

Intracellular Calcium in Red Blood Cells a Common Component in the Molecular Mechanism Causing Anemia? Front. Physiol. 8:673. doi: 10.3389/fphys.2017.00673

\section{Is Increased Intracellular Calcium in Red Blood Cells a Common Component in the Molecular Mechanism Causing Anemia?}

\author{
Laura Hertz ${ }^{1 \dagger}$, Rick Huisjes ${ }^{2 \dagger}$, Esther Llaudet-Planas ${ }^{3}$, Polina Petkova-Kirova ${ }^{1}$, \\ Asya Makhro ${ }^{4}$, Jens G. Danielczok ${ }^{1}$, Stephane Egee ${ }^{5,6,7}$, Maria del Mar Mañú-Pereira ${ }^{3}$, \\ Richard van Wijk ${ }^{2}$, Joan-Lluis Vives Corrons ${ }^{3}$, Anna Bogdanova ${ }^{4}$ and Lars Kaestner ${ }^{8,9 *}$ \\ ${ }^{1}$ Research Centre for Molecular Imaging and Screening, Medical School, Saarland University, Homburg, Germany, \\ ${ }^{2}$ Department of Clinical Chemistry and Haematology, University Medical Center Utrecht, Utrecht, Netherlands, ${ }^{3}$ Red Blood \\ Cell Defects and Hematopoietic Disorders Unit, Josep Carreras Leukaemia Research Institute, Barcelona, Spain, ${ }^{4}$ Red Blood \\ Cell Research Group, Institute of Veterinary Physiology, Vetsuisse Faculty and the Zurich Center for Integrative Human \\ Physiology (ZIHP), University of Zurich, Zurich, Switzerland, ${ }^{5}$ Centre National de la Recherche Scientifique, UMR 8227 \\ Comparative Erythrocyte's Physiology, Roscoff, France, ${ }^{6}$ Université Pierre et Marie Curie, Sorbonne Universités, Roscoff, \\ France, ${ }^{7}$ Laboratoire d'Excellence GR-Ex, Roscoff, France, ${ }^{8}$ Theoretical Medicine and Biosciences, Saarland University, \\ Homburg, Germany, ${ }^{9}$ Experimental Physics, Saarland University, Saarbruecken, Germany
}

For many hereditary disorders, although the underlying genetic mutation may be known, the molecular mechanism leading to hemolytic anemia is still unclear and needs further investigation. Previous studies revealed an increased intracellular $\mathrm{Ca}^{2+}$ in red blood cells (RBCs) from patients with sickle cell disease, thalassemia, or Gardos channelopathy. Therefore we analyzed RBCs' $\mathrm{Ca}^{2+}$ content from 35 patients with different types of anemia (16 patients with hereditary spherocytosis, 11 patients with hereditary xerocytosis, 5 patients with enzymopathies, and 3 patients with hemolytic anemia of unknown cause). Intracellular $\mathrm{Ca}^{2+}$ in RBCs was measured by fluorescence microscopy using the fluorescent $\mathrm{Ca}^{2+}$ indicator Fluo-4 and subsequent single cell analysis. We found that in RBCs from patients with hereditary spherocytosis and hereditary xerocytosis the intracellular $\mathrm{Ca}^{2+}$ levels were significantly increased compared to healthy control samples. For enzymopathies and hemolytic anemia of unknown cause the intracellular $\mathrm{Ca}^{2+}$ levels in RBCs were not significantly different. These results lead us to the hypothesis that increased $\mathrm{Ca}^{2+}$ levels in RBCs are a shared component in the mechanism causing an accelerated clearance of RBCs from the blood stream in channelopathies such as hereditary xerocytosis and in diseases involving defects of cytoskeletal components like hereditary spherocytosis. Future drug developments should benefit from targeting $\mathrm{Ca}^{2+}$ entry mediating molecular players leading to better therapies for patients.

Keywords: rare anemia, erythrocyte, calcium homeostasis, channelopathies, live cell imaging, spherocytosis, xerocytosis 


\section{INTRODUCTION}

Anemia, defined as a hemoglobin concentration $<11-13 \mathrm{~g} / \mathrm{dl}$, based on gender and age, affects 1.6 billion people worldwide (McLean et al., 2009). About 10\% of these individuals are affected by rare anemias. This disease group includes $\sim 90$ different types of red blood cell (RBC) diseases, of which $80 \%$ are hereditary or congenital in nature. As the pathophysiology of most of these rare anemias is poorly understood, the appropriate treatment is often ineffective or even lacking.

Anemia in general has three major causes: blood loss, insufficient hematopoiesis, or facilitated removal of RBCs from the blood stream (Ossendorf, 2003). In hemolytic anemias the $\mathrm{RBC}$ premature clearance and shortened lifespan of RBCs are not compensated by enhanced $\mathrm{RBC}$ production giving rise to anemia (Dhaliwal et al., 2004). Many types of anemia can be assigned to mutations in a single protein. However, it is still unclear how these mutations transfer into an increased clearance of RBCs and what defines heterogeneity in disease severity. A prominent example is sickle cell disease. Described as a molecular disease as early as 1949 (Pauling et al., 1949), sickle cell disease is caused by a single point mutation in the $\beta$-globin gene (Ingram, 1958). The mutated hemoglobin variant, $\mathrm{HbS}$, is prone to polymerization and formation of HbS aggregates, that are even more likely to occur upon dehydration of RBCs (Layton and Nagel, 2010). Dehydration is largely mediated by high intracellular $\mathrm{Ca}^{2+}$, subsequent activation of Gardos Channels and loss of $\mathrm{K}^{+}$(Lew et al., 2002). $\mathrm{Ca}^{2+}$ uptake in sickle RBCs is abnormally high, and not always compensated by $\mathrm{Ca}^{2+}$ extrusion by the $\mathrm{Ca}^{2+}$ pumps resulting in an elevated intracellular $\mathrm{Ca}^{2+}$ content (Eaton et al., 1973; Tiffert et al., 2003). This increase in the $\mathrm{Ca}^{2+}$ content is attributed to highly abundant hyperactive NMDA receptors in membranes of patients' RBCs. Inhibition of $\mathrm{Ca}^{2+}$ uptake via these receptors could prevent dehydration and sickling of RBCs in vitro (Hänggi et al., 2014; Bogdanova et al., 2015). However, it remains elusive, how the mutation in the hemoglobin "causes" the increased $\mathrm{Ca}^{2+}$-influx. The fact that vaso-occlusive crises in sickle cell disease patients occur sporadically (Rieber et al., 1977) points to a rather indirect connection. Increased intracellular $\mathrm{Ca}^{2+}$ levels were also found in RBCs from, e.g., beta thalassemia patients (Bookchin et al., 1988) or patients with Gardos channelopathy (Fermo et al., 2017). It is known that $\mathrm{Ca}^{2+}$ overload triggers several downstream events in RBCs (Bogdanova et al., 2013). One important effect is the impairment of the cytoskeletal stability, e.g., through activation of calpain and subsequent cleavage of membrane associated proteins (Inomata et al., 1993; Salamino et al., 1993). The activation of calmodulin and its interaction with the band $4.1 \mathrm{R}$ protein has been shown to decrease the affinity of $4.1 \mathrm{R}$ for its cytoskeletal interaction partners actin and spectrin and thereby loosening the cytoskeletal structure (Jarret and Kyte, 1979; Nunomura and Takakuwa, 2006). A decreased $\mathrm{RBC}$ volume is resulting from the $\mathrm{Ca}^{2+}$ dependent opening of the Gardos channel, which leads to loss of $\mathrm{K}^{+}, \mathrm{Cl}^{-}$and water (Gardos, 1958). Furthermore, increased $\mathrm{Ca}^{2+}$ levels lead to the disruption of the asymmetrical distribution of phospholipids in the plasma membrane. Phosphatidylserine, a lipid exclusively present in the inner leaflet of the membrane, becomes exposed on the outer membrane by activation of the scramblase and simultaneous inhibition of the flippase (Verkleij et al., 1973; Bitbol et al., 1987; Bassé et al., 1996; Woon et al., 1999). All these described changes in the cell physiology as well as the increased $\mathrm{Ca}^{2+}$ are signs of senescence (sometimes referred to as eryptosis) and prime the cells for clearance from the blood stream (Lutz and Bogdanova, 2013). A substantial increase in intracellular $\mathrm{Ca}^{2+}$ also increases the osmotic fragility with no strict correlation to cell volume and largely before cells reach spherocytic hemolysis volume (Cueff et al., 2010). This might be an additional mechanism of a decrease in RBC number associated to an elevated $\mathrm{Ca}^{2+}$ concentration. To what extent a $\mathrm{Ca}^{2+}$ induced increased vesiculation (Nguyen et al., 2011; Alaarg et al., 2013) may alter the RBC clearance is still unknown.

Here we aim to investigate if elevated intracellular $\mathrm{Ca}^{2+}$ levels are a general feature in the pathophysiology of hemolytic anemia and such provides a mechanistic link for an increased clearance of RBCs resulting in anemia of hemolytic patients.

\section{MATERIALS AND METHODS}

\section{Participants}

Patients diagnosed with different types of anemia were enrolled in the study after signed informed consent. Patient data were handled anonymously as outlined in the ethics applications. These applications were approved by the Medical Ethical Research Board (MERB) of the University Medical Center Utrecht, the Netherlands, (UMCU) under reference code 15/426M "Disturbed ion homeostasis in hereditary hemolytic anemia" and also by the Ethical Committee of Clinical Investigations of Hospital Clinic, Spain, (IDIBAPS) under the reference code 2013/8436. Exclusion criteria were erythrocyte transfusion in the past 90 days, age below 3 years and/or body weight lower than $18 \mathrm{~kg}$. Blood from healthy control donors was anonymously obtained using the approved medical ethical protocol of 07/125 Mini Donor Dienst, also approved by the MERB of UMCU. The blood of the patient and the healthy donor anti-coagulated in lithium-heparin was shipped overnight from the University Medical Center Utrecht (Utrecht, The Netherlands) and from Institut d'Investigacions Biomèdiques August Pi i Sunyer/Hospital Clínic de Barcelona (Barcelona, Spain) to Saarland University (Homburg, Germany). All patients included in this study were genetically screened for mutations by next-generation sequencing and diagnosed with the following types of anemia: 16 patients included in this study were diagnosed with hereditary spherocytosis using golden standard techniques (EMA-binding, osmotic gradient ektacytometry and osmotic fragility test). Moreover, these 16 patients were screened for mutations by next-generation sequencing: 7 patients had mutations in ANK1, 4 patients had mutations in SPTA1, 3 patients in $S P T B$, and 2 patients showed mutations in SLC4A1). Eleven patients were diagnosed with hereditary xerocytosis (due to mutations in PIEZO1), 5 patients had enzymatic disorders (3 patients with glucose-6-phosphate dehydrogenase deficiency, 1 patient with glutamate-cysteine ligase deficiency, 1 patient with glutathione reductase deficiency) and 3 patients suffered from hemolytic anemia of unknown cause. 


\section{Calcium Imaging}

$\mathrm{Ca}^{2+}$ imaging experiments were carried out with RBCs from 35 patient blood samples and 25 healthy transportation controls. Intracellular $\mathrm{Ca}^{2+}$ was measured from single cells as Fluo4 (Thermo Fisher Scientific, Waltham, MA, USA) based fluorescence intensity as described before (Wang et al., 2014).

\section{Data Analysis}

Analysis of the fluorescence images was performed in ImageJ (Wayne Rasband, National Institutes of Health) and further processing of the data was done using Matlab (Mathworks, Natick, MA, USA) and GraphPad Prism (GraphPad Software Inc., La Jolla, CA, USA). For each patient and control at least 200 individual cells were analyzed. The mean fluorescence intensity values were plotted as box-and-whiskers. Boxes show median and 25th to 75th percentiles, whiskers are drawn down to 10th and up to 90th percentile. For cell-based analysis of single patients and controls, significance was checked using the Mann-Whitney test.

For patient-based analysis, patients were grouped in hereditary spherocytosis, hereditary xerocytosis, enzymopathies, and hemolytic anemia of unknown cause. As a statistical basis we used the median fluorescence intensity value from the single cell analysis for each patient and control sample. Intensity values from controls were normalized to their mean value, whereas patients were normalized to the corresponding shipping control. Significance was tested on not normalized raw data using the paired $t$-test when data showed a normal distribution (D'Agostino-Pearson normality test) otherwise with the Wilcoxon signed-rank test.

\section{RESULTS}

In this study, 35 patients with different types of hemolytic anemia were analyzed. Patients were grouped according to their disease into 4 subgroups: hereditary spherocytosis patients, hereditary xerocytosis patients, patients with enzymopathies and patients with unknown hemolytic anemia. For each subgroup, representative fluorescence images of Fluo-4 loaded RBCs from patients and corresponding transportation controls of healthy donors are depicted in Figures 1A-D.

Figures 1E-H show the cell-based statistical analysis for each patient and the corresponding control. Fluo-4 fluorescence intensity from single cells was measured and plotted. There was a huge variation in the intensity-correlated $\mathrm{Ca}^{2+}$ concentrations when comparing the samples taken altogether. However, when we compared samples within a particular shipment (identical transportation conditions), the $\mathrm{Ca}^{2+}$ concentrations were in a similar/comparable range. Therefore we always compared patients exclusively to their corresponding shipping controls.

In all 16 cases of hereditary spherocytosis we found that intracellular $\mathrm{Ca}^{2+}$ levels in RBCs were significantly elevated in patients compared to the corresponding healthy shipping control samples (Figure 1E). In hereditary xerocytosis 9 out of 11 patients showed increased $\mathrm{Ca}^{2+}$ levels, whereas for the other two patients no significant differences could be detected (Figure 1H, P50.1 and P51.2).

The group of unknown hemolytic anemia patients gave a more heterogeneous picture. The $\mathrm{Ca}^{2+}$ content in one patient was significantly increased, whereas the other two patients had significantly lower $\mathrm{Ca}^{2+}$ levels than the shipping control (Figure 1F, P30.1 vs. P31.1 and P32.1). The situation was similar for the enzymopathies: three patients (Figure 1G, P41.1, $\mathrm{P} 42.1, \mathrm{P} 43.1)$ had an increased intracellular $\mathrm{Ca}^{2+}$ content, one was significantly lower and one patient showed no significant difference compared to its control (Figure 1G, P44.1 and P40.1, respectively).

The patient-based statistical analysis of the $\mathrm{Ca}^{2+}$ concentrations is depicted in Figure $\mathbf{2 A}$ and shows the paired and normalized analysis of all patients in comparison to all controls. $\mathrm{Ca}^{2+}$ levels in hemolytic anemia patients show a highly significant increase. Figure 2B shows the same analysis for subgroups of patients. The groups with hereditary spherocytosis and hereditary xerocytosis patients have significantly increased levels of intracellular $\mathrm{Ca}^{2+}$, compared to the controls. Patients with enzymopathies depict an increase in the intracellular $\mathrm{Ca}^{2+}$ concentration but fail to reach significant changes. For patients with hemolytic anemia of unknown cause intracellular $\mathrm{Ca}^{2+}$ levels appear to be heterogeneous, because it is a non-systematic group composition.

\section{DISCUSSION}

\section{$\mathrm{Ca}^{2+}$ Overload}

In this study we monitored the intracellular $\mathrm{Ca}^{2+}$ levels in RBCs from patients with several types of hemolytic anemia. We found that in the analyzed cases of membranopathies, hereditary spherocytosis and hereditary xerocytosis, intracellular $\mathrm{Ca}^{2+}$ is significantly increased. Figure $2 \mathrm{C}$ depicts the proposed mechanism. Starting with the previously described sickle cell disease (compare Introduction) an increased number of NMDA receptors were identified to cause the abnormal uptake of $\mathrm{Ca}^{2+}$ (Hänggi et al., 2014). In vitro, this increase in $\mathrm{Ca}^{2+}$ can be reduced by NMDA blockers like Memantine and a pilot clinical trial investigating the effect of this drug on sickle cell disease patients is closed and the statistical analysis is currently on-going (Bogdanova et al., 2017). For other types of anemia the $\mathrm{Ca}^{2+}$ entry pathways are rather unclear. In the Gardos channelopathy it is suggested that $\mathrm{Ca}^{2+}$ enters via the mechanical activated Piezo1 channel (Fermo et al., 2017). We found several different mutations for the PIEZO1 gene in the xerocytosis patients included in our study. A further characterization of how these mutations affect the physiology of the channel is still ongoing, but data in the literature show that six dehydrated hereditary stomatocytosis-causing mutations in the Piezol channel with five of them in the C-terminal $1 / 5$ of the protein, result in a slowing of the inactivation kinetics of the channel and thus to a more active channel (Albuisson et al., 2013). However, independent of $\mathrm{Ca}^{2+}$ entry pathways also an impairment of $\mathrm{Ca}^{2+}$ extrusion (of residual $\mathrm{Ca}^{2+}$ influx) needs to be considered as an important factor for the $\mathrm{Ca}^{2+}$ homeostasis in RBCs. The plasma membrane $\mathrm{Ca}^{2+}$ ATPase (PMCA) is the only known active extrusion pathway for $\mathrm{Ca}^{2+}$ in $\mathrm{RBCs}$ and its transportation capacity is limited by the availability of ATP (Schatzmann, 1966; Pasini et al., 2006). It has been reported that Piezol can regulate the ATP release from human RBCs and that mutations in the channel can alter the released amount of ATP (Cinar et al., 2015). Therefore it 
A Hereditary spherocytosis

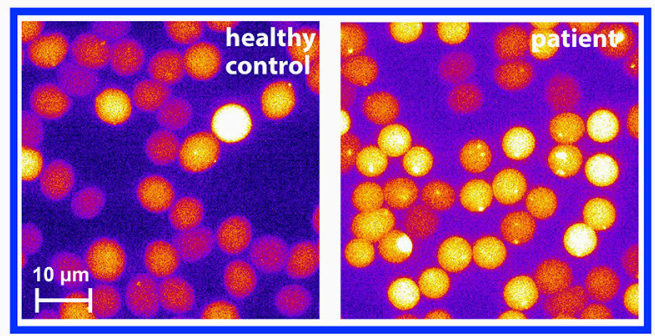

C Enzymopathies

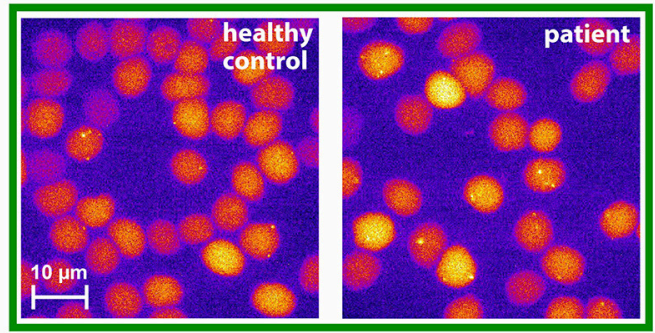

B Hemolytic anemia

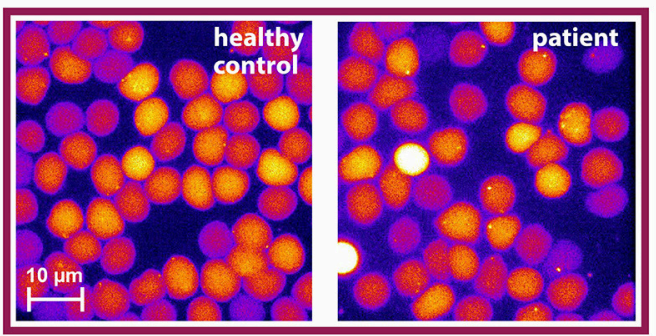

D Hereditary xerocytosis

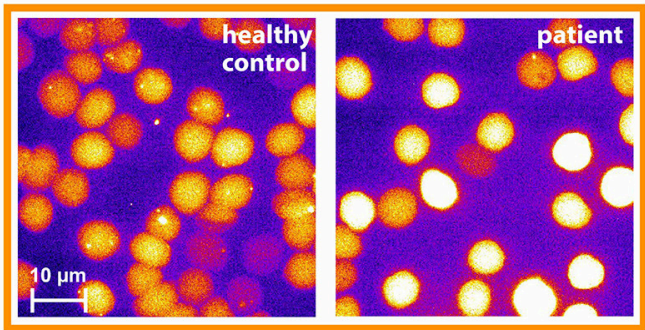

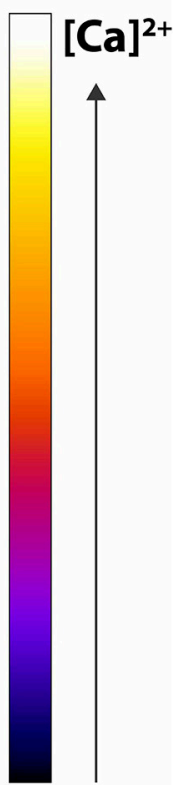

E intracellular $\mathrm{Ca}^{2+}$ in patients with hereditary spherocytosis

F intracellular $\mathrm{Ca}^{2+}$ in patients

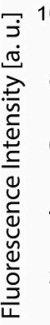
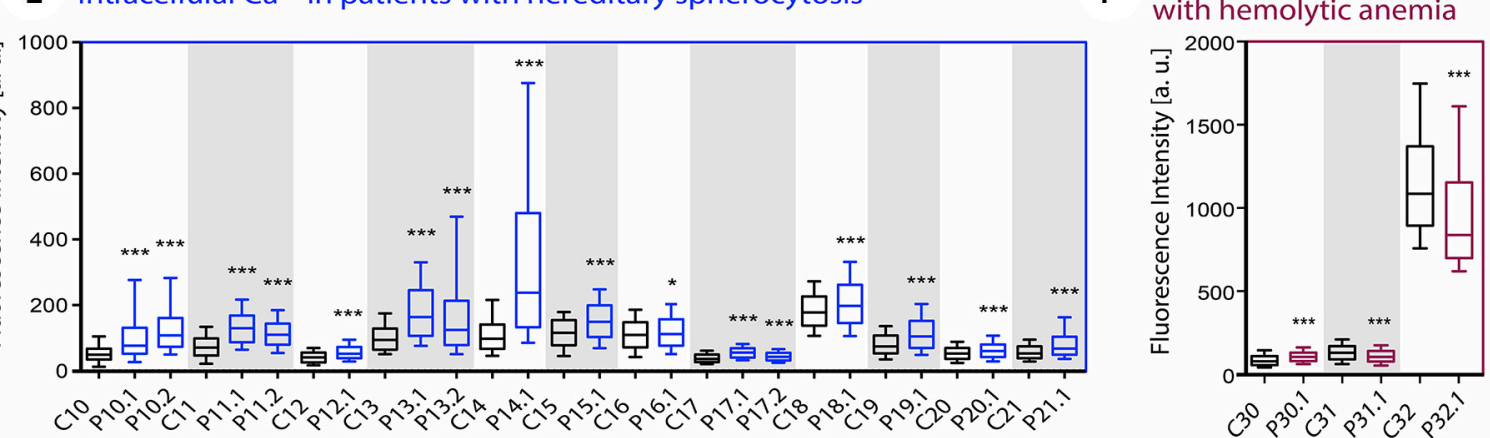

G intracellular $\mathrm{Ca}^{2+}$ in patients with enzymopathies

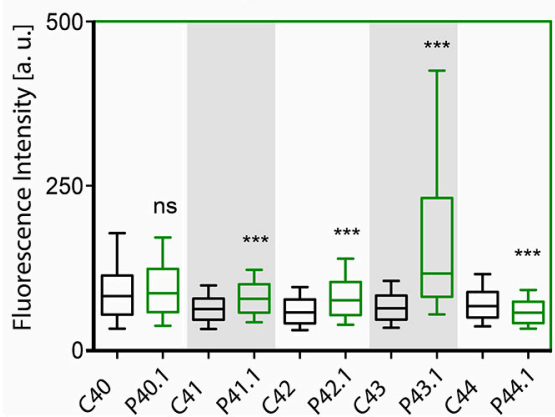

$\mathbf{H} \quad$ intracellular $\mathrm{Ca}^{2+}$ in patients with hereditary xerocytosis

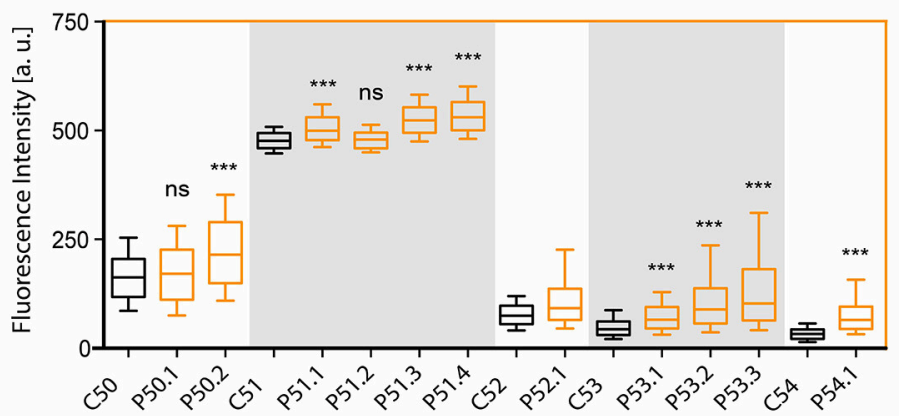

FIGURE 1 | Intracellular $\mathrm{Ca}^{2+}$ content in RBCs from patients with different types of hemolytic anemia. (A-D) Representative fluorescence images of Fluo-4 loaded RBCs from control and patient blood samples. Relative intracellular $\mathrm{Ca}^{2+}$ concentration is scaled from black (lowest) to white (highest). Patients were grouped according to their disease diagnosis: hereditary spherocytosis (blue), hemolytic anemia (purple), enzymopathies (green), hereditary xerocytosis (orange).

(E-H) Statistical analysis of the mean Fluo-4 intensity values in arbitrary units from single cells for each group of patients and the corresponding control samples. Controls and patients that belong to the same shipment are highlighted with a white or gray background. Controls are displayed as black boxes, patients are colored in blue (hereditary spherocytosis), purple (unknown hemolytic anemia), green (enzymopathies), and orange (hereditary xerocytosis). Whiskers indicate the range between 10 th and 90th percentiles. There is a huge variation in the intensity-correlated $\mathrm{Ca}^{2+}$ concentrations already within the control group of healthy donors. Significance was tested between each patient and the according shipping control sample (always the next control sample on left side) using the Mann-Whitney test (ns denotes $p>0.5,{ }^{*} p \leq 0.5,{ }^{\star * \star} p \leq 0.01$ ). 


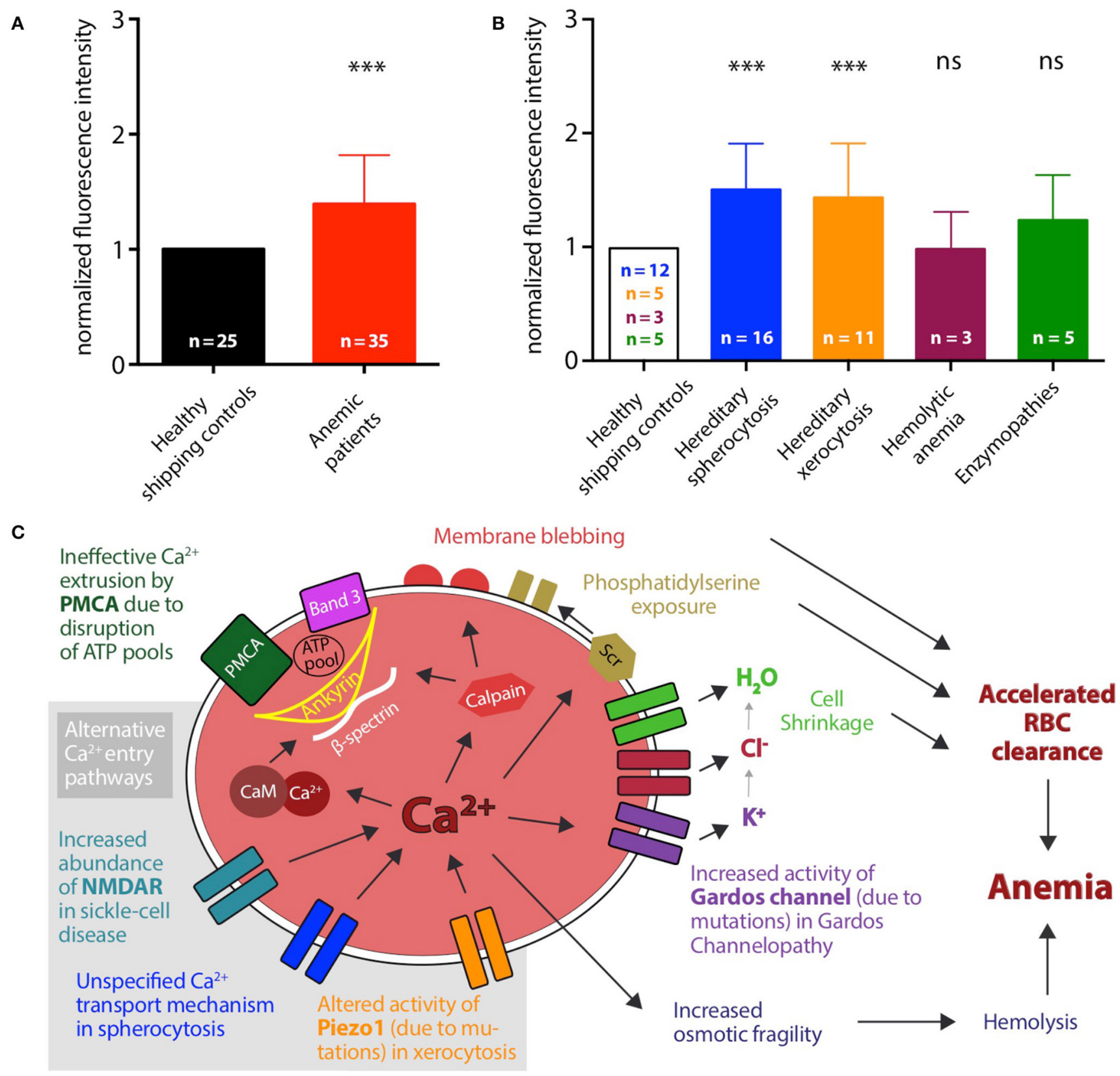

FIGURE 2 | Patient-based statistical analysis of intracellular $\mathrm{Ca}^{2+}$ levels and proposed mechanisms. (A) Statistical analysis of normalized median fluorescence intensity values for all 35 patients (red bar) and 25 healthy shipping controls (black bar). Significance was tested using the Wilcoxon signed-rank test ( $\left.{ }^{\star \star \star} p \leq 0.01\right)$. (B) Statistical analysis of normalized median fluorescence intensity values for controls and patients grouped by disease. Number of control samples differs for each disease group. Hereditary spherocytosis (blue): 16 patients and 12 controls, hereditary xerocytosis (orange): 12 patients and 5 controls, hemolytic anemia (purple): 3 patients and 3 controls, enzymopathies (green): 5 patients and 5 controls. Significance was tested using the paired $t$-test, when data showed a Gaussian distribution (D'Agostino-Pearson normality test), otherwise using the Wilcoxon signed-rank test (ns denotes $p>0.5$, ${ }^{\star \star \star} p \leq 0.01$ ). (C) Proposed mechanisms leading to increased intracellular $\mathrm{Ca}^{2+}$ levels in diseased RBCs and accordingly to accelerated clearance of cells from the blood stream. Alternative or cumulating Ca ${ }^{2+}$ entry pathways are highlighted with gray background: increased abundance of NMDA-receptors (NMDAR), e.g., in sickle cell disease, altered activity of Piezo1, e.g., in hereditary xerocytosis, increased activity of Gardos Channel, e.g., in Gardos Channelopathy, or unspecified Ca ${ }^{2+}$ transport mechanisms. Additionally, ineffective extrusion of $\mathrm{Ca}^{2+}$ due to disruption of ATP pools fueling the plasma membrane $\mathrm{Ca}^{2+}$ ATPase (PMCA) can contribute. Several downstream processes follow Ca ${ }^{2+}$ overload in RBCs, e.g.: activation of calmodulin by formation of the $\mathrm{Ca}^{2+}$-calmodulin complex (Ca-CaM) and activation of calpain, thereby loosening the cytoskeletal structure; activation of the scramblase (Scr) leading to exposure of phosphatidylserine on the outer leaflet of the membrane; activation of the Gardos channel followed by the efflux of $\mathrm{K}^{+}, \mathrm{Cl}^{-}$and $\mathrm{H}_{2} \mathrm{O}$ and consecutive cell shrinkage. 
is also possible that the detected $\mathrm{Ca}^{2+}$ overload in $\mathrm{RBCs}$ from xerocytosis patients is due to ATP depletion and ineffective $\mathrm{Ca}^{2+}$ extrusion. This would imply that glycolytic enzyme defects of the $\mathrm{RBC}$, generally considered to lead to decreased ATP levels, would result in $\mathrm{Ca}^{2+}$ overload. The ATP needed to fuel the pump is trapped in membrane-associated complexes (ATP pools). Among others, identified components of these complexes are Band 3, ankyrin, and $\beta$-spectrin (Chu et al., 2012). Mutations in these proteins are found in the spherocytosis patients included in this study. If these mutations lead to a disruption of the complexes serving as ATP pools for the $\mathrm{Ca}^{2+}$ pump, the extrusion of $\mathrm{Ca}^{2+}$ will also be significantly reduced. Likewise, the general cytoskeleton stability is impaired in RBCs from spherocytosis patients. Changes in the mechanical stability of the cells may result in an activation of mechanosensitive channels, like Piezo1, again leading to an increase in intracellular $\mathrm{Ca}^{2+}$. Both components (increased $\mathrm{Ca}^{2+}$ leak and decreased $\mathrm{Ca}^{2+}$ extrusion) could happen independent of each other or even mutually reinforce. We can exclude that the different values in fluorescence intensity are due to changes in cell volume: In a different study we tested volume changes, e.g., by osmotic swelling, and costained RBCs with Calcein Red-Orange, a dye insensitive to the $\mathrm{Ca}^{2+}$ concentration and intensity changes were negligible compared to intensity changes occurring in measurements probing the RBCs $\mathrm{Ca}^{2+}$ concentration (Danielczok et al., 2015). The delicate balance between $\mathrm{Ca}^{2+}$ entry and exit is likely to be influenced by mechanical stress. During their journey in the blood stream, RBCs experience hundreds squeezes when passing small capillaries and the spleen. To perform such experiments in artificial circulation systems in vitro became recently available based on microfluidic devices (Brust et al., 2014; Danielczok et al., 2015; Picot et al., 2015) and should be a future experimental focus.

The results we report do have a therapeutic impact: they illustrate that disease specific pharmacological targets should be upstream of the increase in intracellular $\mathrm{Ca}^{2+}$ to avoid all $\mathrm{Ca}^{2+}$ related effects that accumulate the processes facilitating $\mathrm{RBC}$ clearance as outlined in Figure 2C. In contrast pharmacological targets downstream of the action of intracellular $\mathrm{Ca}^{2+}$ may fail to address the major symptoms of the disease as it was shown for the Gardos channel inhibitor Senicapoc. In sickle cell disease patients it failed to improve acute vaso-occlusive crises (Ataga et al., 2011).

\section{Blood Shipment}

Having a critical look at our data from Figures 1E-H it is evident that the transportation process has a huge impact on the measured intracellular $\mathrm{Ca}^{2+}$ content in RBCs. Differences (within controls) are mainly not due to different transportation times (which were similar for all shipments) but to different transportation conditions, like temperature, vibration intensity and duration or other shipment related parameters that are

\section{REFERENCES}

Alaarg, A., Schiffelers, R. M., van Solinge, W. W., and van Wijk, R. (2013). Red blood cell vesiculation in hereditary hemolytic anemia. Front. Physiol. 4:365. doi: 10.3389/fphys.2013.00365 out of our control. We choose Heparin as an anticoagulant because it does not interfere with the extracellular $\mathrm{Ca}^{2+}$. Other standard anticoagulants like CPDA or EDTA bind the external $\mathrm{Ca}^{2+}$, making internal $\mathrm{Ca}^{2+}$ measurements unreliable (Makhro et al., 2016). In the mentioned study transportation was simulated under laboratory conditions, which shows better results than the inconsistency of control samples within the present experiments (Figures 1E-H). In addition we do not know if intracellular $\mathrm{Ca}^{2+}$ levels during transportation are more severely influenced in patient RBCs compared to healthy controls, which presents an uncertainty of this study. Therefore future studies require investigations without cellular convolution by the shipment process, i.e., either a travel of the patient to specialized laboratories for single cell investigations or the establishment of such specialized mobile laboratories.

\section{CONCLUSION}

Considering our $\mathrm{Ca}^{2+}$ data and the results from studies on sickle cells and RBCs from patients with Gardos channelopathies, there is strong evidence that the $\mathrm{Ca}^{2+}$ overload in RBCs contributes to their accelerated clearance from the circulation and is a common part of the molecular mechanism in these types of anemia. The exact molecular regulation of the $\mathrm{Ca}^{2+}$ entry pathways requires further investigations. Future drug developments should benefit from targeting $\mathrm{Ca}^{2+}$ entry mediating molecular players, as, e.g., Memantine for the treatment of sickle cell disease patients (Bogdanova et al., 2017), leading to better therapies for patients.

\section{AUTHOR CONTRIBUTIONS}

LK, AB, RvW, JV defined the study and planed the experiments. LH, RH, EL, PP, JD, AM, MdM performed the acquisition and analysis. LH, SE, and LK interpreted the data. LH and LK drafted the manuscript. AB, RvW, JV, RH, SE, EL, PP, JD, AM, MdM critically revised the manuscript. All authors approved the final version of the manuscript.

\section{FUNDING}

The research leading to these results has received funding from the European Seventh Framework Program under grant agreement number 602121 (CoMMiTMenT) and the European Framework "Horizon 2020" under grant agreement number 675115 (RELEVANCE).

\section{ACKNOWLEDGMENTS}

We would like to thank Prof. Peter Lipp (Institute for Molecular Cell Biology, Saarland University, Homburg/Saar, Germany) for letting us use the laboratory.

Albuisson, J., Murthy, S. E., Bandell, M., Coste, B., Louis-dit-Picard, H. L. N., Mathur, J., et al. (2013). Dehydrated hereditary stomatocytosis linked to gain-of-function mutations in mechanically activated PIEZO1 ion channels. Nat. Commun. 4, 165-119. doi: 10.1038/ncomms 2899 
Ataga, K. I., Reid, M., Ballas, S. K., Yasin, Z., Bigelow, C., James, L. S., et al. (2011). Improvements in haemolysis and indicators of erythrocyte survival do not correlate with acute vaso-occlusive crises in patients with sickle cell disease: a phase III randomized, placebo-controlled, double-blind study of the Gardos channel blocker senicapoc (ICA-17043). Br. J. Haematol. 153, 92-104. doi: $10.1111 / j .1365-2141.2010 .08520 . x$

Bassé, F., Stout, J. G., Sims, P. J., and Wiedmer, T. (1996). Isolation of an erythrocyte membrane protein that mediates $\mathrm{Ca}^{2+}$-dependent transbilayer movement of phospholipids. J. Biol. Chem. 271, 17205-17210. doi: 10.1074/jbc.271.29.17205

Bitbol, M., Fellmann, P., Zachowski, A., and Devaux, P. F. (1987). Ion regulation of phosphatidylserine and phosphatidylethanolamine outside-inside translocation in human erythrocytes. Biochim. Biophys. Acta 904, 268-282. doi: 10.1016/0005-2736(87)90376-2

Bogdanova, A., Makhro, A., and Kaestner, L. (2015). "Calcium handling in red blood cells of sickle cell disease patients," in Sickle Cell Disease, ed M. E. Lewis (Hauppauge, NY: Nova Science Publishers), 29-60.

Bogdanova, A., Makhro, A., Seiler, E., Gassmann, M., Hegemann, I., Muller, R., et al. (2017). "N-methyl D-glutamate receptor as a pharmacological target for treatment of sickle cell disease: effect of memantine on red cells of patients on a pilot clinical trial MemSID," in 21th Meeting of the European Red Cell Society (Heidelberg). Abstract nr S03-02.

Bogdanova, A., Makhro, A., Wang, J., Lipp, P., and Kaestner, L. (2013). Calcium in red blood cells-a perilous balance. Int. J. Mol. Sci. 14, 9848-9872. doi: 10.3390/ijms 14059848

Bookchin, R. M., Ortiz, O. E., Shalev, O., Tsurei, S., Rachmilewitz, E. A., Hockaday, A., et al. (1988). Calcium transport and ultrastructure of red cells in betathalassemia intermedia. Blood 72, 1602-1607.

Brust, M., Aouane, O., Thi baud, M., Flormann, D., Verdier, C., Kaestner, L., et al. (2014). The plasma protein fibrinogen stabilizes clusters of red blood cells in microcapillary flows. Sci. Rep. 4:4348. doi: 10.1038/srep04348

Chu, H., Puchulu-Campanella, E., Galan, J. A., Tao, W. A., Low, P. S., and Hoffman, J. F. (2012). Identification of cytoskeletal elements enclosing the ATP pools that fuel human red blood cell membrane cation pumps. Proc. Natl. Acad. Sci. U.S.A. 109, 12794-12799. doi: 10.1073/pnas.1209014109

Cinar, E., Zhou, S., DeCourcey, J., Wang, Y., Waugh, R. E., and Wan, J. (2015). Piezo1 regulates mechanotransductive release of ATP from human RBCs. Proc. Natl. Acad. Sci. U.S.A. 112, 11783-11788. doi: 10.1073/pnas.1507309112

Cueff, A., Seear, R., Dyrda, A., Bouyer, G., Eg e, S. P., Esposito, A., et al. (2010). Effects of elevated intracellular calcium on the osmotic fragility of human red blood cells. Cell Calcium 47, 29-36. doi: 10.1016/j.ceca.2009.11.002

Danielczok, J., Ruppenthal, S., Terriac, E., Lautenschläger, F., Lipp, P., and Kaestner, L. (2015). "Evidence for PIEZO1 involvment in pressure-dependent $\mathrm{Ca}^{2+}$-increase in human red blood cells," in 20th Meeting of the European Red Cell Society (Roscoff). Abstract nr 54.

Dhaliwal, G., Cornett, P., and Tierney, L. M. J. (2004). Hemolytic Anemia. Am. Fam. Physician 69, 2599-2606. Available online at: http://www.aafp.org/afp/ 2004/0601/p2599.html

Eaton, J. W., Jacob, H. S., Skelton, T. D., Swofford, H. S., and Kolpin, C. E. (1973). Elevated Erythrocyte Calcium in Sickle Cell Disease. Nature 246, 105-106. doi: $10.1038 / 246105 \mathrm{a} 0$

Fermo, E., Bogdanova, A., Petkova-Kirova, P., Zaninoni, A., Marcello, A. P., Makhro, A., et al. (2017). 'Gardos Channelopathy': a variant of hereditary Stomatocytosis with complex molecular regulation. Sci. Rep. 7:1744. doi: 10.1038/s41598-017-01591-w

Gardos, G. (1958). The function of calcium in the potassium permability of human erythrocytes. Biochim. Biophys. Acta 30, 653-654. doi: 10.1016/0006-3002(58)90124-0

Hänggi, P., Makhro, A., Gassmann, M., Schmugge, M., Goede, J. S., Speer, O., et al. (2014). Red blood cells of sickle cell disease patients exhibit abnormally high abundance of $\mathrm{N}$-methyl $\mathrm{D}$-aspartate receptors mediating excessive calcium uptake. Br. J. Haematol. 167, 252-264. doi: 10.1111/bjh.13028

Ingram, V. M. (1958). Abnormal human haemoglobins. I. The comparison of normal human and sickle-cell haemoglobins by fingerprinting. Biochim. Biophys. Acta 28, 539-545. doi: 10.1016/0006-3002(58)90516-X

Inomata, M., Nakamura, M., Imajoh-Ohmi, S., and Kawashima, S. (1993). A variety of calpain/calpastatin systems in mammalian erythrocytes. Biochim. Biophys. Acta 1178, 207-214. doi: 10.1016/0167-4889(93)90011-D

Jarret, H. W., and Kyte, J. (1979). Human erytrocyte calmodulin. J. Biol. Chem. 254, $8237-8244$.
Layton, D. M., and Nagel, R. L. (2010). "Hemoglobinopathies due to structural mutations," in Molecular Hematology, eds D. Provan and J. G. Gribben (Chicester: Wiley-Blackwell), 179-195.

Lew, V. L., Etzion, Z., and Bookchin, R. M. (2002). Dehydration response of sickle cells to sickling-induced Ca. Blood 99, 2578-2585. doi: 10.1182/blood.V99.7.2578

Lutz, H. U., and Bogdanova, A. (2013). Mechanisms tagging senescent red blood cells for clearance in healthy humans. Front. Physiol. 4:387. doi: 10.3389/fphys.2013.00387

Makhro, A., Huisjes, R., Verhagen, L. P., Ma-ú-Pereira, M. D. M., Llaudet-Planas, E., Petkova-Kirova, P., et al. (2016). Red cell properties after different modes of blood transportation. Front. Physiol. 7:288. doi: 10.3389/fphys.2016.00288

McLean, E. E., Cogswell, M. M., Egli, I. I., Wojdyla, D. D., and de Benoist, B. B. (2009). Worldwide prevalence of anaemia, WHO vitamin and mineral nutrition information system, 1993-2005. Public Health Nutr. 12, 444-454. doi: $10.1017 /$ S1368980008002401

Nguyen, D. B., Wagner-Britz, L., Maia, S., Steffen, P., Wagner, C., Kaestner, L., et al. (2011). Regulation of phosphatidylserine exposure in red blood cells. Cell. Physiol. Biochem. 28, 847-856. doi: 10.1159/000335798

Nunomura, W., and Takakuwa, Y. (2006). Regulation of protein 4.1R interactions with membrane proteins by $\mathrm{Ca}^{2+}$ and calmodulin. Front. Biosci. 11, 1522-1539. doi: $10.2741 / 1901$

Ossendorf, M. (2003). "Erythrozyten," in Integrative Klinische Chemie und Laboratoriumsmedizin Pathophysiologie, Pathobiochemie, Hämatologie, ed H. Renz (Berlin; New York, NY: de Gruyter), 157-184.

Pasini, E. M., Kirkegaard, M., Mortensen, P., Lutz, H. U., Thomas, A. W., and Mann, M. (2006). In-depth analysis of the membrane and cytosolic proteome of red blood cells. Blood 108, 791-801. doi: 10.1182/blood-2005-11-007799

Pauling, L., Itano, H. A., Singer, S. J., and Wells, I. C. (1949). Sickle cell anemia a molecular disease. Science 110, 543-548. doi: 10.1126/science.110.2865.543

Picot, J., Ndour, P. A., Lefevre, S. D., El Nemer, W., and Tawfik, H., Galimand, J., et al. (2015). A biomimetic microfluidic chip to study the circulation and mechanical retention of red blood cells in the spleen. Am. J. Hematol. 90, 339-345. doi: 10.1002/ajh.23941

Rieber, E. E., Veliz, G., and Pollack, S. (1977). Red cells in sickle cell crisis: observations on the pathophysiology of crisis. Blood 49, 967-979.

Salamino, F., De Tullio, R., Mengotti, P., Viotti, P. L., Melloni, E., and Pontremoli, S. (1993). Site-directed activation of calpain is promoted by a membrane-associated natural activator protein. Biochem. J. 290, 191-197. doi: 10.1042/bj2900191

Schatzmann, H. J. (1966). ATP-dependent $\mathrm{Ca}^{++}$-extrusion from human red cells. Experientia 22, 364-365. doi: 10.1007/BF01901136

Tiffert, T., Bookchin, R. M., and Lew, V. L. (2003). "Calcium homeostasis in normal and abnormal human red cells," in Red Cell Membrane Transport in Health and Disease, eds I. Bernhardt and J. C. Ellory (Berlin; Heidelberg: Springer), 373-405.

Verkleij, A. J., Zwaal, R. F., Roelofsen, B., Comfurius, P., Kastelijn, D., and van Deenen, L. L. (1973). The asymmetric distribution of phospholipids in the human red cell membrane. A combined study using phospholipases and freeze-etch electron microscopy. Biochim. Biophys. Acta 323, 178-193. doi: 10.1016/0005-2736(73)90143-0

Wang, J., van Bentum, K., Sester, U., and Kaestner, L. (2014). Calcium homeostasis in red blood cells of dialysis patients in dependence of erythropoietin treatment. Front. Physiol. 5:16. doi: 10.3389/fphys.2014.00016

Woon, L. A., Holland, J. W., Kable, E. P. W., and Roufogalis, B. D. (1999). Ca ${ }^{2+}$ sensitivity of phospholipid scrambling in human red cell ghosts. Cell Calcium 25, 313-320. doi: 10.1054/ceca.1999.0029

Conflict of Interest Statement: The authors declare that the research was conducted in the absence of any commercial or financial relationships that could be construed as a potential conflict of interest.

Copyright (c) 2017 Hertz, Huisjes, Llaudet-Planas, Petkova-Kirova, Makhro, Danielczok, Egee, del Mar Mañú-Pereira, van Wijk, Vives Corrons, Bogdanova and Kaestner. This is an open-access article distributed under the terms of the Creative Commons Attribution License (CC BY). The use, distribution or reproduction in other forums is permitted, provided the original author(s) or licensor are credited and that the original publication in this journal is cited, in accordance with accepted academic practice. No use, distribution or reproduction is permitted which does not comply with these terms. 